\title{
Supporting Resilience in the Academic Setting for Student Soldiers and Veterans as an Aspect of Community Reintegration: The Design of the Student Veteran Project Study
}

\begin{abstract}
Alexa M. Smith-Osborne
Abstract: The Post 9/11 GI Bill is leading an increasing proportion of wounded warriors to enter universities. This paper describes the design and development of an adapted supported education intervention for veterans. The intervention trial was one of two projects which grew out of a participatory action research process aimed at supporting reintegration of returning veterans into the civilian community. This intervention is being tested in a foundation-funded randomized controlled trial in a large southwestern university, with participation now extended to student-veterans at colleges around the country. Some protective mechanisms which were found in theory and in prior research were also supported in early results. SEd intervention was associated with the protective mechanisms of support network density, higher mood, and resilience. Practitioners may benefit from the lessons learned in the development of this supported education intervention trial when considering implementation of this complementary intervention for veterans reintegrating into civilian life.
\end{abstract}

Keywords: Veterans, resilience, supported education, psychiatric rehabilitation, GI Bill

\section{INTRODUCTION}

The Department of Defense (DoD) has initiated innovative efforts to support mission readiness and prevent mental health problems among troops in current conflicts. These efforts use two theoretical frameworks, resilience and positive psychology, which show goodness of fit with military emphasis on proactive preparedness and adaptive fitness and training (e.g., Britt, Adler, \& Bartone, 2001; Castro, 2008; Cornum, Matthews, \& Seligman, 2011; Mojica, 2010; Office of the U.S. Army Surgeon General, 2003, 2008, 2009; Orsingher, Lopez, \& Rinehart, 2008).

Community institutions which serve military members and families, taking over educational, health, and social service delivery from DoD institutions when military service is done, may enhance continuity of care and community reintegration by adopting service models consistent with these theoretical frameworks. Choice of theory has important implications for measurement (Luthar, 1993, Luthar \& Cushing, 1999), goodness of fit of intervention with target group (Greene, 2007; Holter, Mowbray, Bellamy, MacFarlane, \& Dukarski, 2004; Luthar, Sawyer, \& Brown, 2006), and fidelity of intervention implementation (Bond, Evans, Salyers, Williams, \& Kim, 2000; Borrelli et al., 2005). Academic settings are one important community institution for returning service members, as pursuing higher education has been identified as a key goal for

\footnotetext{
Alexa Smith-Osborne, Ph.D. is assistant professor of social work, University of Texas at Arlington. Support for the preparation of this article was given by a University of Texas Arlington research enhancement grant and a grant from the Hogg Foundation for Mental Health.
}

Copyright (C) 2012 Advances in Social Work Vol. 13 No. 1 (Spring 2012), 34-50 
today's All Volunteer Force (AVF) soldiers (Asch, Fair, \& Kilburn, 2000; Fernandez, 1980; National Priorities Project, 2006), including those with this combat era's signature conditions (Hall, 2009; Tanelian \& Jaycox, 2008). This paper describes the design and development of an innovative intervention utilizing a resilience theoretical framework to support community reintegration via the academic setting, and reports first wave results.

\section{THEORETICAL CONSIDERATIONS: WHO MAY BENEFIT FROM SUPPORTED EDUCATION FOR VETERANS AND THROUGH WHAT MECHANISMS}

This author's prior resiliency-based research has suggested several potential protective mechanisms which may operate to support educational attainment for AVF veterans with mental health risks and service-connected disabilities (Smith-Osborne, 2009a; 2009b). Further, evidence-based practices in supported education (SEd) have already been established for the civilian college population with psychiatric disabilities (Anthony \& Unger, 1991; Holter, Mowbray, Bellamy, MacFarlane, \& Dukarski, 2004; National Public Radio, 2002); approaches to their wider dissemination have also been investigated (Mowbray, Bellamy, Megivern, \& Szilvagyi, 2001; Mowbray, Moxley, \& Brown, 1993). How might supported education, adapted to a resilience theory framework consistent with military prevention programs, operate to promote recovery, community reintegration, and advancement for military/veterans in the academic setting?

The resilience theoretical paradigm would indicate that supported education can operate by four protective processes against mental health risk (Rutter, 1990). Initial findings from this intervention trial (reported below) suggest that supported education intervention for this population may operate by several of these processes. The first type of protective process reduces the risk impact, which could be suggested in this intervention trial by reduced or stable levels of symptoms (e.g., post-test PTSD symptoms) for the intervention group compared to unchanged or increased symptoms for the control group while functioning in the academic setting. Operation of the second type of process, to reduce negative chain reactions stemming from the risk factor, would be suggested by unchanged or decreased post-test resilience scores in the control group compared to increased or sustained scores in the intervention group. The third type of process promotes resiliency traits, which could be suggested by higher posttest scores on resilience and associated evidence-based protective factors (such as informational support network measures) for the intervention group. The fourth type of process operates by setting up new opportunities for success. The recent passage of expanded financial aid benefits under the new post 9/11 GI Bill represents one such opportunity (McChesney, 2008; Merrow, 2008). However, prior research suggests that the GI Bill alone may not be sufficient to support veterans' access to higher education without effective collateral social, health, academic, and income support systems (Smith-Osborne, 2009a; 2009b). Brokering of concrete and informational resources necessary to educational success (e.g., internships, scholarships, faculty mentoring, family income support, and child care) is a component of supported education models (Anthony \& Ungar, 1991; Mowbray, 2002). Intervention effects on educational attainment variables such as college entry, use of non- 
VA as well as VA financial aid, grade point average, and retention could provide evidence that supported education operates by this process.

A parallel theoretical paradigm which may be useful is the job control model for high demand and ambiguous work contexts (Dubow, Schmidt, McBride, Edwards, \& Merk, 1993; Karasek, 1979). Ambiguity may characterize academic settings as contrasted with the more highly structured and directive military occupational setting (although both are high demand). This model suggests that increased latitude (relative flexibility and autonomy) in making decisions about work methods and scheduling mediates ambiguity and conflicting demands so as to prevent burnout. From this perspective, a preventive mechanism by which supported education could support resilience is through providing targeted consultation and mentoring to student veterans in exercising decision latitude in their educational decisions, thus preventing emotional exhaustion which may be related to school drop-out (Hobfall, 1989; Hobfall, Johnson, Ennis, \& Jackson, 2003; Meilman, Manley, Gaylor, \& Turco, 1992). Thus, a supported education model such as the ChooseGet-Keep program (Collins, Mowbray, \& Bybee, 1999), which utilizes an explicit goalsetting and decision-making protocol, may operate via increasing decision latitude to prevent emotional exhaustion and (potentially) college drop out.

A higher proportion of AVF troops are married with families, compared to earlier combat era cohorts (Defense Manpower Data Center, 2008; Karney \& Crown, 2007), suggesting that family resilience may also need to be addressed in order to support student veteran resilience. Lavee, McCubbin, and Patterson's double ABCX model of Family Adjustment and Adaptation (1985) has been used to investigate military families under stress and to suggest ways to enhance family resilience in earlier conflicts (McCubbin \& Dahl, 1976; McCubbin, Dahl, Lester, Benson, \& Robertson, 1976; McCubbin, Hunter, \& Dahl, 1975). The double ABCX model highlights the importance of family appraisals of the associated hardships, and of the perceived resources and vulnerabilities for dealing with them, rather than solely the stressors themselves. The later revised version, the Resiliency Model of Family Adjustment and Adaptation, includes post-crisis variables descriptive of the long-term adaptation phase (McCubbin \& McCubbin, 1991), suggesting goodness of fit for supported education intervention.

\section{STUDENT VETERAN PROJECT INTERVENTION DESIGN}

Current service delivery systems and models are reported to have limitations in reaching and serving AVF personnel with service-connected co-morbid conditions (Batten \& Pollack, 2008; Hoge, Auchterlonie, \& Milliken, 2006; Seal et al., 2010). Design and development of innovative interventions for this population must address these limitations, as well as be based on applicable substantive theory and empirical efficacy and effectiveness evidence. Therefore, the design of the target intervention began with a participatory action research (PAR) approach (Viswanathan et al., 2004) to engaging a range of stakeholders in the community, the VA, and higher education settings in the identification of these limitations and how they could be addressed in connection with veterans' educational goals (Smith-Osborne, 2009c). From this process emerged two trajectories: the development of efforts to enhance a veteran-friendly campus at the host institution under the auspices of a newly created interdepartmental 
steering committee (being studied as implementation research [Fixsen, Naoom, Blase, Friedman, \& Wallace, 2005] using mixed methods) and the development of a randomized clinical trial of an adapted manualized supported education program with a comparison "usual care" group and a wait-listed control group. This paper reports on the second effort.

The clinical trial, entitled the Student Veteran Project, selected the Choose-Get-Keep supported education model (Sullivan, Nicolellis, Stanley, \& MacDonald-Wilson, 1993) as the experimental intervention due to its established efficacy and effectiveness with civilian populations, the consistency of its goal-setting emphasis with the job control theoretical model, and its consistency as a psychosocial rehabilitation program with resilience and family resilience theory (Carpenter, 2002), as described above. This Choose-Get-Keep model has a manualized protocol developed by the Boston University Center for Psychiatric Rehabilitation (Knighton, McNamara, \& Nemec, 2002) which is being slightly adapted for veterans with the participation of a student-veteran advisory group. The manual identifies more than 70 practitioner skills that facilitate client success in the educational environment; examples are requesting assistance, taking notes, developing a study plan, budgeting, recognizing conflict signs, disclosing disability information, requesting feedback, and responding to feedback. In the interest of fidelity and generalizability, the adaptations are limited to the skills practice components (e.g., role play scenarios) of the lesson plan modules. They are modified to reflect typical student veteran environment: for example, a house share with other veterans, some of whom are non-students, rather than a residential rehabilitation program, and budgeting which includes a VA disability pension instead of a Supplemental Security Income benefit.

A protocol for the comparison group was developed based on information and referral case management strategies commonly used in academic advising and retention of non-traditional students (Astone \& Schoen, 2000; Calloway \& Jorgensen, 1990; Ofiesh, Rice, Long, Merchant, \& Gajar, 2002; Paul, 2000; Rummel, Costello, Acton, \& Pielow, 1990; Swail, Redd, \& Perna, 2003; Weiner \& Wiener, 1997). Such strategies typically use student-accessed online information platforms, and case management through email and telephone follow-up, so this "usual care" group protocol emphasizes these technology-mediated contacts.

Prior research (Smith-Osborne, 2005; 2009a; 2009b) provided the foundation for intervention design, identifying resilience protective mechanisms moderating or mediating the impact of mental health risk factors on educational attainment at the personal, interpersonal, and systems (see Figure 1); they are incorporated in both the target intervention model and in usual care, and are communicated in study recruitment as well as during the setting of intervention goals. 


\section{METHOD}

\section{Design}

As introduced above, one result of the PAR process was the development of a three group randomized controlled clinical trial of SEd for veterans returning to college. Procedures for random assignment and allocation concealment are described in SmithOsborne $(2008 ; 2009$ c).

Figure 1. Empirically identified protective factors applied within the selected theoretical frameworks incorporated within the target and comparison interventions.

RESILIENCE AND FAMILY RESILIENCE THEORY

JOB CONTROL THEORY

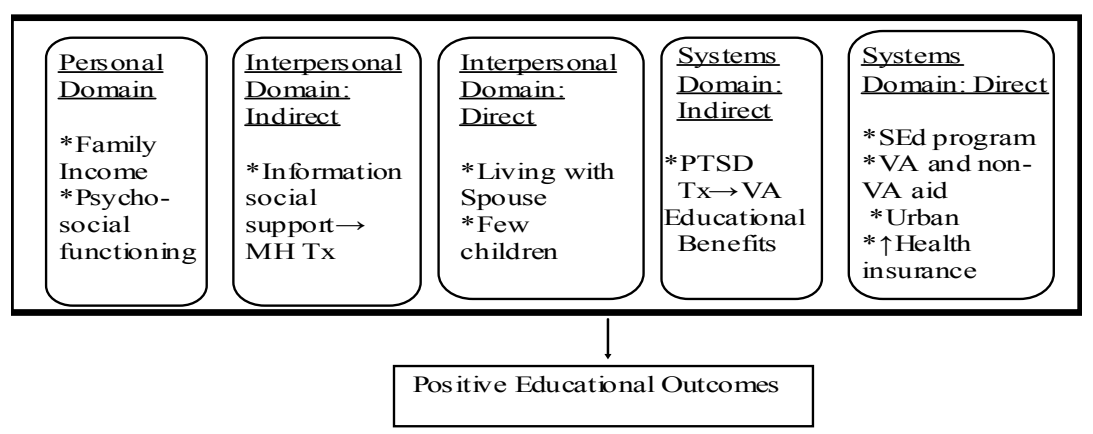

$\mathrm{MH}=$ mental health; $\mathrm{Tx}=$ treatment $\mathrm{PTSD}=$ Posttraumatic Stress Disorder; VA = Veterans Administration; $\mathrm{SEd}=$ supported education program.

\section{Sample Recruitment}

Approval was obtained from the author's Institutional Review Board (protocol 07.225s). Participants are recruited at community events, employment offices, veteran services, and colleges (see Figure 2).

\section{MEASURES AND PROCEDURES}

\section{Measures}

Participants complete questionnaires at pre-random assignment, post-intervention period, 6 months follow-up, and 12 months follow-up. Data on contact frequency and type ("dosage"), health status, and mental health treatment engagement are collected from case records maintained during the intervention period and from qualitative interviews. Baseline analyses examine demographics and measures of resilience (Resilience Scale for Adults), social support (Perceived Neighborhood Scale), social 
network density (Density of Support), PTSD (PTSD Checklist-Military), mood (Short Mood and Feeling Questionnaire), and substance abuse (CAGE-AID). A complete description of measures may be found in Smith-Osborne (2008) and of the conceptual and logic and measurement model in Smith-Osborne (2009c).

Figure 2. Participant flow chart following Consolidated Standards of Reporting Trials guidelines. ITT $=$ intent to treat.

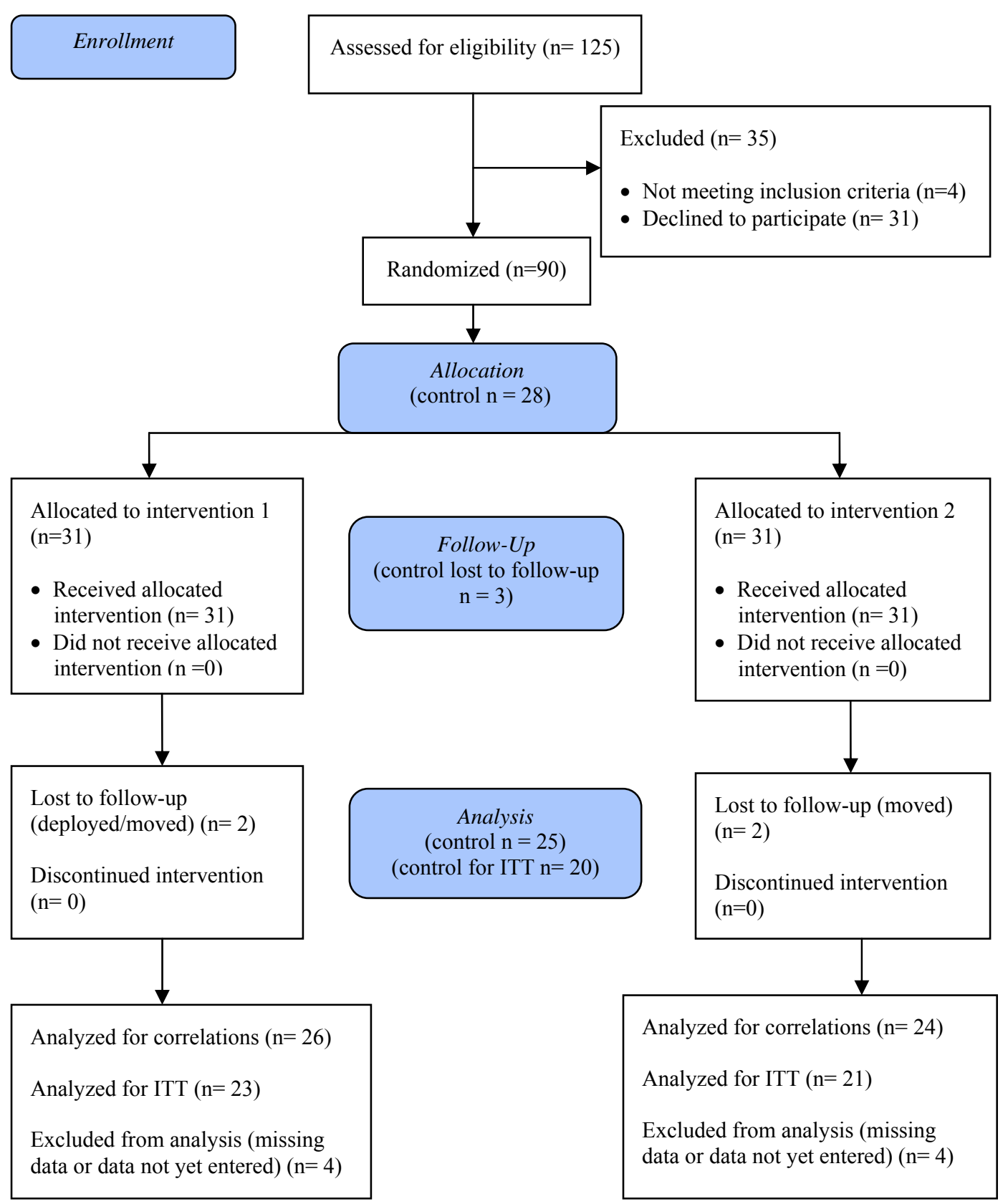




\section{Intervention Fidelity Strategies}

Fidelity procedures were developed and progressively refined during this design phase of the project (Smith-Osborne, 2011). Fidelity ratings enhance validity in clinical trials, and provide an important base for translation of results to implementation as evidence-based practices by community providers (Borrelli et al., 2005; Greenhalgh, Robert, Macfarlane, Bate, \& Kyriakidou, 2004; Mowbray, Holter, Teague, \& Bybee, 2003). Fidelity strategies recommended by Borelli et al. (2005) were utilized. Intervention adherence was assessed for the following standards. Intervention dose consists of a standardized 1 hour intake interview, followed by contact sessions over 26-30 weeks. The minimum 4 sessions for the manualized intervention (group 1) are 1.5-2 hour sessions. The minimum 4 sessions for group 2 are delivered through an online platform, email, telephone, and face to face contact. Contact $\geq 30$ minutes addressing an intervention goal are counted and online platform use is tracked. Videotapes of the experimental intervention and progress notes of the usual care comparison were also rated by a trained practitioner panel using a standardized checklist.

\section{Staff Training}

During the PAR phase of intervention development, prior to intervention delivery, online training modules were developed and pilot-tested for this study to provide training in military culture and benefit structures, to support implementation of the Choose-GetKeep manualized protocol with a military population, to support uniform implementation of the usual care services, and to provide grounding in the theoretical framework and targeted protective mechanisms. All providers used a standardized intake format (Cournoyer, 2008) and Study-specific multi-component (Herschell, Kolko, Baumann, \& Davis, 2010) training and supervision.

\section{DATA ANALYSIS}

\section{Baseline Data}

See Table 1 for sample characteristics. This population resembles the average demographics of AVF veterans, except for higher educational level at time of study enrollment (AVF average is 14 years, the same as draft-era Vietnam veterans; SmithOsborne, 2009a). Descriptive, bivariate $(\mathrm{n}=75)$, and multiple regression analyses $(\mathrm{n}=$ 26) using SPSS 17.0 of the developmental phase sample examine demographic and key risk and protective factors for baseline and short term (pre/post) completers (Little, 1995; Pocock, 1992; Schulz \& Grimes, 2005a, 2005b).

Exploratory analyses of the key factor of resilience were repeated using intent to treat procedures $(n=64)$. Intent to treat analyses use the entire sample that was randomized regardless of intervention dosage/participation. These linear mixed model repeated measure analyses for the two time points with multiple imputations for missing values were conducted using SAS 9.0 (Abraha \& Montedori, 2010; Cook \& DeMets, 2008; Singer, 1998). This type of intent to treat analysis is more robust in handling groups of 
unequal sizes, non-normal data, and categorical and continuous variables in longitudinal data in clinical trials, thus reducing error and increasing statistical power (Beunckens, Molenberghs, Verbeke, \& Mallinckrodt, 2008; Frison \& Pocock, 1992; Keselman, Algina, \& Kowalchuk, 2001). Effect sizes Cohens $d$ statistic were calculated for T1 versus T2 for each condition for $t$ test and mixed model analyses.

Table 1. Baseline Characteristics by Group ( $(n=75)$

\begin{tabular}{|c|c|c|c|}
\hline Variables & $\begin{array}{c}\text { Group } 1(\mathbf{n}=\mathbf{2 6}) \\
\% \text { or } M(\mathrm{SD})\end{array}$ & $\begin{array}{c}\text { Group } 2(\mathbf{n}=24) \\
\% \text { or } M(\mathrm{SD})\end{array}$ & $\begin{array}{c}\text { Group } 3(\mathbf{n}=\mathbf{2 5}) \\
\% \text { or } M(\mathrm{SD})\end{array}$ \\
\hline \multicolumn{4}{|l|}{ Gender: } \\
\hline $\begin{array}{l}\text { Male } \\
\text { Female }\end{array}$ & $\begin{array}{l}84 \% \\
16 \%\end{array}$ & $\begin{array}{l}56 \% \\
40 \%\end{array}$ & $\begin{array}{l}88 \% \\
8 \%\end{array}$ \\
\hline Age & $32.68(10.92)$ & $31.83(8.45)$ & $32.67(11.44)$ \\
\hline \multicolumn{4}{|l|}{ Ethnicity: } \\
\hline $\begin{array}{l}\text { Non-minority } \\
\text { Minority }\end{array}$ & $\begin{array}{l}52 \% \\
48 \%\end{array}$ & $\begin{array}{l}64 \% \\
32 \%\end{array}$ & $\begin{array}{l}56 \% \\
36 \%\end{array}$ \\
\hline \multicolumn{4}{|l|}{ Marital Status } \\
\hline $\begin{array}{l}\text { Married, Living with Spouse } \\
\text { Other }\end{array}$ & $\begin{array}{l}32 \% \\
68 \%\end{array}$ & $\begin{array}{l}32 \% \\
64 \%\end{array}$ & $\begin{array}{l}36 \% \\
56 \%\end{array}$ \\
\hline Education in Yrs. (range 12-18) & $14.12(1.54)$ & $14.15(1.39)$ & $14.11(1.29)$ \\
\hline Used nonVA Aid & $40 \%$ & $64 \%$ & $36 \%$ \\
\hline Used VA Aid & $84 \%$ & $72 \%$ & $76 \%$ \\
\hline Learning Disability & $24 \%$ & $24 \%$ & $32 \%$ \\
\hline Health Status (range 1-4) & $1.76(.83)$ & $1.92(.88)$ & $1.91(.95)$ \\
\hline \# Health Conditions & $2.04(1.34)$ & $1.42(.83)$ & $2.00(1.27)$ \\
\hline Resilience (range 74-210) & $161.18(31.49)$ & $157.41(34.56)$ & $137.50(40.26)$ \\
\hline Mood (range 19-39) & $34.95(3.41)$ & $33.94(16.45)$ & $34.00(5.05)$ \\
\hline Social Support (range 4-46) & $28.44(12.85)$ & $24.61(10.35)$ & $28.22(13.19)$ \\
\hline Network Density (range 0-16) & $8.33(4.79)$ & $6.91(4.79)$ & $5.95(5.08)$ \\
\hline Alcoholism (range 0-2) & $1.00(.00)$ & $.58(.33)$ & $.88(.6)$ \\
\hline PTSD (range 17-26) & $36.09(19.82)$ & $34.61(19.13)$ & $35.10(18.76)$ \\
\hline
\end{tabular}

Note. Percentages may not total $100 \%$ due to missing data.

\section{Completion Rate and Fidelity of Implementation}

Eighty percent of group 1 participants and $83 \%$ of group 2 participants completed the minimum four contact sessions. One control group member and no intervention group members who were enrolled in college in the pilot phase at Time 1 dropped out by Time 2 . Fidelity for the group 1 manualized model was rated as moderate overall $\left(M_{\text {range 1-5 }}=\right.$ 
3.67, $S D=1.34$ ), although interrater agreement on the dichotomous items (e.g., worker referred to lesson plan during session: yes/no) was low (Fleiss's kappa $=0.22$; Fleiss, 1971). Eighty-three percent of participants in the pilot phase met both fidelity criteria of completion rate and contact content analysis findings.

\section{Protective and Risk Factors}

Initially, after analyses for descriptive statistics and assumption tests were done, Pearson's $r$ correlations were analyzed to focus on one risk and one protective predictor variable identified in prior cross-sectional research and resilience theory and on experimental condition (group) that had significant relationships at the .05 level with the risk and potential protective factors. The predictors found to be significant in the bivariate analyses were intervention group assignment, which was correlated with the potential protective factors of denser support networks $(r=-.41, p<.05)$, and control group assignment, which was correlated with higher levels of the risk factor PTSD symptoms $(r$ $=.47, p<.05)$.

In multiple regression completer analyses $(n=26)$, intervention was significantly related to higher post social network density scores $\left(\mathrm{B}=3.66, p=.04, \mathrm{R}^{2}=18.5 \%\right.$, Adj. $\left.\mathrm{R}^{2}=14.8 \%\right)$ and control group with higher post PTSD symptom scores $(\mathrm{B}=-15.54, p=$ $.03, \mathrm{R}^{2}=17.4 \%$, Adj. $\mathrm{R}^{2}=14 \%$ ). Consistent with prior cross-sectional research, these findings suggest that supported education interventions may increase social support as a protective factor and reduce PTSD as a risk factor for educational attainment. The effect size is weak to moderate (Cohen, 1988).

Resilience is a key protective factor postulated by the theoretical framework of the trial. Therefore, exploratory completer and intent to treat analyses were performed. Paired sample completer t tests $(n=26)$ suggested that neither intervention group had significantly changed in resilience scores $\left(\mathrm{t}_{25}=.057, p=.96\right)$, whereas the control group decreased significantly from pre to post $\left(\mathrm{t}_{25}=-3.30 ; p=.01\right)$. Findings suggest that supported education intervention may support resilience in the experience of stressors associated with reentry into the civilian life trajectory of college attendance. Intent to treat analyses were conducted using the SAS multiple imputation procedure for missing data. Mixed models with six fixed effects, plus intercept, were fit to these data. The six effects were group assignment, gender, race, marital status, time (1 and 2), and GPA, with experimental groups 1 and 2 contrasted to control group 3. Mixed repeated measure group effects for resilience in the intent to treat group and in the paired sample $t$ test for the completer group were statistically significant. These data suggest that intervention (both groups combined) compared to wait list is significantly associated with higher resilience scores at posttest. The effect size is moderate for both conditions, consistent with the literature.

\section{LESSONS LEARNED AND APPLICATIONS TO PRACTICE}

Completion rates of the minimum intervention "dosage" were acceptable. Early nonutilization rates led to an additional search of the clinical trial literature (e.g., Cooper et al., 2009) and early adoption of an evidence-based procedure of conducting pre- 
randomization and then final randomization assignment after eligibility confirmation, informed consent completion, and completion of the intake interview for all participants. Fidelity findings were mixed for the manualized protocol, leading to plans for the addition of a fidelity checklist to each group 1 case record, as well as protocol readiness checklist at each training session. Fidelity levels for usual care met expectations, both for common treatment elements (Hart, 2009) and elements specific to technology-enhanced services (Parasuraman, Ziethaml, \& Malhotra, 2005). Fidelity and attrition prevention will be further supported by addition of an automated voicemail and cell text service, currently in field testing, to issue reminders for referrals, appointments, and posttests and collect data on responses to monitor follow-through. This interactive web phone technology will be used in applications to prevent or determine the cause of missed classes/appointments and to inform participants' case managers.

This report on project development examined a limited number of protective factors targeted in intervention from Time 1 to Time 2. Some protective mechanisms which were found in theory and in prior cross-sectional and meta-analytic research were also supported in these findings: intact nuclear family, resilience, and VA and non-VA financial aid were correlated with educational attainment, while SEd intervention was associated with support network density, higher mood, and resilience. This may suggest that practitioners, be proactive in providing or brokering couples and family counseling and support services for families of student veterans, despite eligibility limitations on university mental health services, some private health insurance, and some VA services which exclude couples counseling or a non-student spouse for services. Practitioners with this population need to attend to concrete resources, including all forms of financial aid, concomitantly with clinical services, consistent with a generalist social work model. Of course, these preliminary findings are cautiously reported due to their consistency with the prior literature, since instability of results can characterize early phases of a longitudinal clinical trial. Results become more reliable and stable as sample size increases (Schulz \& Grimes, 2005b).

Next steps in this research will implement examination of possible differences in effectiveness of the two experimental conditions in an enlarged sample over additional time points. Since the study will include multiple measures of several key variables, it will be possible to consider differences among outcome variables depending on measure, which were beyond the scope of this initial report. Future reports will also address theoretical implications of the results for resilience theory development and suggest future research to examine the alternative decision-making model using, for example, emotional exhaustion measures.

\section{References}

Abraha, I., \& Montedori, A. (2010). Modified intention to treat reporting in randomized controlled trials: Systematic review. British Medical Journal, 340, c2697.

doi:10.1136/bmj.c2697 
Anthony, W. A., \& Unger, K. V. (1991). Supported education: an additional program resource for young adults with long-term mental illness. Community Mental Health Journal, 27, 145-156.

Asch, B. J., Fair, C. C., \& Kilburn, M. R. (2000). An assessment of recent proposals to improve the Montgomery GI Bill. Santa Monica, CA: Rand Corporation. (NTIS No. ADA380619)

Astone, N. M., \& Schoen, R. (2000). School reentry in early adulthood: the case of inner city African Americans. Sociology of Education, 73, 133-155.

Batten, S. V., \& Pollack, S. J. (2008). Integrative outpatient treatment for returning service members. Journal of Clinical Psychology, 64, 928-939.

Beunckens, C., Molenberghs, G., Verbeke, G., \& Mallinckrodt, C. (2008). A latent-class mixture model for incomplete longitudinal Gaussian data. Biometrics, 64, 96-105.

Bond, G. R., Evans, L., Salyers, M. P., Williams, J., \& Kim, H.-W. (2000). Measurement fidelity in psychiatric rehabilitation. Mental Health Services Research, 2, 75-87.

Borrelli, B., Sepinwall, D., Ernst, D., Bellg, A. J., Czajkowski, S., Breger, R., et al. (2005). A new tool to assess treatment fidelity and evaluation of treatment fidelity across 10 years of health behavior research. Journal of Consulting and Clinical Psychology, 73, 852-860.

Britt, T. W., Adler, A. B., \& Bartone, P. T. (2001). Deriving benefits from stressful events: The role of engagement in meaningful work and hardiness. Journal of Occupational Health Psychology, 6, 53-63.

Calloway, M. D., \& Jorgensen, L. B. (1990). A model program for returning women in higher education. College Student Journal, 28, 281-286.

Castro, C. A. (2008). Battlemind as a foundation for building psychological resilience. Retrieved on from www.dcoe.health.mil/event docs/WRC.

Cohen, J. (1988). Statistical power analysis for the behavioral sciences ( $2^{\text {nd }}$ ed.). New York: Lawrence Erlbaum Associates.

Collins, M. E., Mowbray, C. T., \& Bybee, D. (1999). Establishing individualized goals in a supported education intervention: Program influences on goal-setting and attainment. Research on Social Work Practice, 9, 483-507.

Cook, T. D., \& DeMets, D.L. (Eds.). (2008). Introduction to statistical methods for clinical trials. Boca Raton, FL: Chapman \& Hall/CRC.

Cooper, L. A., Roter, D. L., Bone, L. R., Larson, S. M., Miller, E. R., Barr, M. S., . . Levine, D. M. (2009). A randomized controlled trial of interventions to enhance patient-physician partnership, patient adherence and high blood pressure control among ethnic minorities and poor persons: Study protocol NCT00123045. Implementation Science, 4, 7-23. doi: 10.1186/1748-5908-4-7 
Cornum, R., Matthews, M. D., \& Seligman, M. E. P. (2011). Comprehensive Soldier Fitness: Building resilience in a challenging institutional environment. American Psychologist, 66, 4-9. doi: 10.1037/a0021420

Cournoyer, B. (2008). The social work skills workbook ( $5^{\text {th }}$ ed.). Belmont, CA.: Brooks/Cole.

Defense Manpower Data Center (DMDC) (2008). Active Duty Demographic Profile. Retrieved from www.deomi.org/home/saveCountFiles.cfm?fileid=280.

Dubow, E. F., Schmidt, D., McBride, J., Edwards, S., \& Merk, F. L. (1993). Teaching children to cope with stressful experiences: initial implementation and evaluation of a primary prevention program. Journal of Clinical Child Psychology, 22(4), 428-440.

Fernandez, R. L. (1980). Issues in the Use of Post-Service Educational Benefits as Enlistment Incentives (No. RAND Note N-1510-MRAL). Santa Monica, California: RAND Corporation.

Fixsen, D. L., Naoom, S. F., Blase, K. A., Friedman, R. M., \& Wallace, F. (2005). Implementation Research: A Synthesis of the Literature (No. (FMHI Publication \#231)). Tampa, FL: University of South Florida, Louis de la Parte Florida Mental Health Institute, The National Implementation Research Network.

Fleiss, J. L. (1971). Measuring nominal scale agreement among many raters. Psychological Bulletin, 76, 378-382.

Frison, L., \& Pocock, S. J. (1992). Repeated measures in clinical trials: Analysis using mean summary statistics and its implications for design. Statistics in Medicine, 11, 1685-1704.

Greene, R. R. (2007). Social work practice: A risk and resilience perspective. Belmont, CA: Thomson Brooks Cole.

Greenhalgh, T., Robert, G., Macfarlane, F., Bate, P., \& Kyriakidou, O. (2004). Diffusion of innovations in service organizations: Systematic review and recommendations. Milbank Quarterly, 82, 581-629.

Hall, K. (2009, July 5). Colleges focus on veterans as expanded GI Bill raises enrollment. The Boston Globe. Retrieved from http://www.boston.com

Hart, T. (2009). Treatment definition in complex rehabilitation interventions. Neuropsychological Rehabilitation, 19, 824-840.

Herschell, A. D., Kolko, D. J., Baumann, B. L., \& Davis, A. C. (2010). The role of therapist training in the implementation of psychosocial treatments: A review and critique with recommendations. Clinical Psychology Review, 30, 448-466.

Hobfall, S. E. (1989). Conservation of resources--A new attempt at conceptualizing stress. American Psychologist, 44, 513-524. 
Hobfall, S. E., Johnson, R. J., Ennis, N., \& Jackson, A. P. (2003). Resource loss, resource gain, and emotional outcomes among inner city women. Journal of Personality and Social Psychology, 84(3), 632-643.

Hoge, C. W., Auchterlonie, J., \& Milliken, C. S. (2006). Mental health problems, use of mental health services, and attrition from military service after returning from deployment to Iraq or Afghanistan. Journal of the American Medical Association, 295, 1023-1032.

Holter, M. C., Mowbray, C. T., Bellamy, C. D., MacFarlane, P., \& Dukarski, J. (2004). Critical ingredients of consumer run services: Results of a national survey. Community Mental Health Journal, 40, 47-63.

Karasek, R. (1979). Job demands, job decision latitude and mental strain: Implications for job redesign. Administrative Science Quarterly, 24, 285-306.

Karney, B. R., \& Crown, J. S. (2007). Families under stress: An assessment of data, theory, and research on marriage and divorce in the military. Santa Monica, CA: The RAND Corporation.

Keselman, H. J., Algina, J., \& Kowalchuk, R. K. (2001). The analysis of repeated measures designs: A review. British Journal of Mathematical and Statistical Psychology, 54, 1-20.

Knighton, D., McNamara, S., \& Nemec, P. B. (2002). Psychiatric rehabilitation practitioner tools: Achieving valued roles "Compendium Version"-Educational environments. Boston, MA: Boston University Center for Psychiatric Rehabilitation Consulting, Inc.

Lavee, Y., McCubbin, H. I., \& Patterson, J. (1985). The double ABCX model of family stress and adaptation: An empirical test by analysis of structural equations with latent variables. Journal of Marriage and the Family, 47, 811-825.

Little, R. J. A. (1995). Modeling the drop-out mechanism in repeated-measures studies. Journal of the American Statistical Association, 90, 1112-1121.

Luthar, S. S. (1993). Annotation: Methodological and conceptual issues in research on child resilience. Journal of Child Psychology and Psychiatry, 34(4) 441-453.

Luthar, S. S., Cicchetti, D., \& Becker, B. (2000). The construct of resilience: A critical evaluation and guidelines for future work. Child Development, 71(3) 543-562.

Luthar, S. S., \& Cushing, G. (1999). Measurement of issues in the empirical study of resilience: An overview. In M. D. Glantz \& J. L. Johnson (Eds.), Resilience and development: Positive life adaptions (pp. 129-160). New York, NY: Kluwer Academic/Plenum Publishers.

Luthar, S. S., Sawyer, J. A., \& Brown, P. (2006). Conceptual issues in studies of resilience. Annals of the New York Academy of Sciences, 1094(1), 105-115.

McChesney, J. (2008). Morning edition: GI Bill proposal expands college benefits for vets. [Online broadcast]. New York and Washington, DC: Public Broadcasting 
Service. Retrieved from the Public Broadcasting Service website at: http://www.npr.org/templates/story/story.php?storyId=89913867

McCubbin, H. I., \& Dahl, B. B. (1976). Prolonged family separation in the military: A longitudinal study. In H. I. McCubbin, B. B. Dahl, \& E. J. Hunter (Eds.), Families in the military system (pp. 112-144). Beverly Hills, CA: Sage.

McCubbin, H. I., Dahl, B. B., Lester, G. R., Benson, D., \& Robertson, M. L. (1976). Coping repertoires of families adapting to prolonged war-induced separations. Journal of Marriage and the Family, 38, 461-471.

McCubbin, H. I., Hunter, E. J., \& Dahl, B. B. (1975). Residuals of war: Families of prisoners of war and servicemen missing in action. Journal of Social Issues, 31, 95109.

McCubbin, M. A., \& McCubbin, H. I. (1991). Resiliency in families: A conceptual model of family adjustment and adaptation in response to stress and crises. In H. I. McCubbin, A. I. Thompson, \& M. A. McCubbin (Eds.), Family assessment: Resiliency, coping, and adaptation---Inventories for research and practice (pp. 1-64). Madison, WI: University of Wisconsin System.

Meilman, P. W., Manley, C., Gaylor, M., \& Turco, J. (1992). Medical withdrawals from college for mental health reasons and their relation to academic performance. Journal of American College Health, 40, 217-223.

Merrow, J. (2008, February 12). Online news hour: War vets still struggle with education costs, despite G. I. Bill benefit. [Online broadcast]. New York and Washington, DC: Public Broadcasting Service. Retrieved from http://www.pbs.org/newshour/bb/military/jan-june08/gibill_02-12.html

Mojica, J.A. (2010). Army Reserve Suicide Prevention Program information briefing. Retrieved from http://www.health.mil/dhb/downloads/TaskForce2010/6 March\%2011\%20Task\%20 Force $\% 20$ Meeting\%20Materials/Presentations/Mojica_Suicide $\% 20$ Prevention $\% 20 \mathrm{Br}$ iefing-v11-1-Keessee.pdf

Mowbray, C. T. (2002). Supported education and psychiatric rehabilitation: Models and methods. Columbia, MD: International Association of Psychosocial Rehabilitation Services.

Mowbray, C. T., Holter, M. C., Teague, G. B., \& Bybee, D. (2003). Fidelity criteria: Development, measurement, and validation. American Journal of Evaluation, 24, 315-340.

Mowbray, C. T., Moxley, D. P., \& Brown, K. S. (1993). A framework for initiating supported education programs. Psychosocial Rehabilitation Journal, 17, 129-150.

National Priorities Project. (2006, December 22). Military recruiting 2006. Retrieved from the National Priorities Project website at http://www.nationalpriorities.org/Publications/Military-Recruiting-2006.html 
National Public Radio. (2002, August 13). Colleges address student depression: Campuses adapt to needs of the mentally ill. Retrieved from http://www/npr.org/programs/morning/features/2002/aug/mentalhealth/index.html

Ofiesh, N. S., Rice, C. J., Long, E. M., Merchant, D. C., \& Gajar, A. H. (2002). Service delivery for post-secondary students with disabilities: a survey of assistive technology use across disabilities. College Student Journal, 36, 94-108.

Office of the US Army Surgeon General. (2003). Operation Iraqi Freedom (OIF) Mental Health Advisory Team (MHAT) Report 16 December 2003. Retrieved from http://www.armymedicine.army.mil/reports/mhat/mhat/mhat_report.pdf.

Office of the US Army Surgeon General. (2008). Mental Health Advisory Team V Report. Retrieved from http://www.armymedicine.army.mil/reports/mhat/mhat_v/mhat-v.cfm.

Office of the US Army Surgeon General. (2009) Mental Health Advisory Team VI Report. Retrieved from http://www.armymedicine.army.mil/reports/mhat/mhat_vi/MHAT_VIOIF EXSUM.pdf.

Orsingher, J. M., Lopez, A. T., \& Rinehart, M. E. (2008). Battlemind training system: “Armor for your mind". The United States Army Medical Department Journal, 3, $66-71$.

Parasuraman, A., Ziethaml, V. A., \& Malhotra, A. (2005). E-S-QUAL: A multiple-item scale for assessing electronic service quality. Journal of Service Research, 7, 213233.

Paul, S. (2000). Students with disabilities in higher education: A review of the literature. College Student Journal, 34, 200-210.

Pocock, S. J. (1992). When to stop a clinical trial. British Medical Journal, 305, 235-240.

Rummel, A., Acton, D., Costello, S., \& Pielow, G. (1999). Is all retention good? An empirical study. College Student Journal, 33, 241-146.

Rutter, M. (1990). Psychosocial resilience and protective mechanisms. In J. Rolf, A. Masten, D. Cichetti, H. H. Neuchterlein, \& S. Weintraub (Eds.), Risk and protective factors in the development of psychopathology (pp. 181-214). Cambridge, England: Cambridge University Press.

Schulz, K. F., \& Grimes, D. A. (2005a). Multiplicity in randomized trials I: Endpoints and treatments. Lancet, 365, 1591-1595.

Schulz, K. F., \& Grimes, D. A. (2005b). Multiplicity in randomized trials II: Subgroup and interim analyses. Lancet, 365, 1657-1661.

Seal, K. H., Maguen, S., Cohen, B., Gima, K. S., Metzler, T. J., Ren, L., . . Marmar, C. R. (2010). VA mental health services utilization in Iraq and Afghanistan veterans in the first year of receiving new mental health diagnoses. Journal of Traumatic Stress, 23, 5-16. 
Singer, J. D. (1998). Using SAS PROC MIXED to fit multilevel models, hierarchical models, and individual growth models. Journal of Educational and Behavioral Statistics, 24, 323-355.

Smith-Osborne, A. (2005). Antecedents to postsecondary educational attainment for individuals with psychiatric disorders: a meta-analysis. Best Practices in Mental Health: An International Journal, 1, 15-30.

Smith-Osborne, A. (2007). Life span and resiliency theory: A critical review. Advances in Social Work, 8, 162-178.

Smith-Osborne, A. (2008). Addressing the mental health needs of returning combat veterans in the community: Studying a supported education program (NIMH grant proposal). Arlington, TX: University of Texas at Arlington School of Social Work.

Smith-Osborne, A. (2009a). Does the GI Bill support educational attainment for veterans with disabilities? Implications for current veterans in resuming civilian life. Journal of Sociology \& Social Welfare, 36, 111-125.

Smith-Osborne, A. (2009b). Mental health risk and social ecological variables associated with educational attainment among Gulf War veterans: Implications for current veterans in returning to civilian life in the community. American Journal of Community Psychology, 44, 327-337.

Smith-Osborne, A. (2009c). Research Enhancement Project final report: Examining the impact of a supported education intervention on student-veterans' educational attainment and resilience. An unpublished report prepared for Research Enhancement Grant Office, Office of Research Administration. Arlington, TX: University of Texas at Arlington.

Smith-Osborne, A. (2011). Final report for the Hogg Foundation for Mental Health: The Student Veteran Project-An intervention trial in supported education. An unpublished report prepared for the Hogg Foundation for Mental Health. Austin, TX: Hogg Foundation for Mental Health.

Sullivan, A. P., Nicolellis, D. L., Stanley, K. S., \& MacDonald-Wilson, K. (1993). Choose-Get-Keep: A psychiatric rehabilitation approach to supported education. Psychosocial Rehabilitation Journal, 17, 55-58.

Swail, W. S., Redd, K. E., \& Perna, L. W. (2003). Retaining minority students in higher education: A framework for success (ASHE-ERIC Higher Education Report Vol. 30, No. 2). Retrieved from the ERIC Higher Education website: http://eriche.org/publications

Tanelian, T., \& Jaycox, L. H. (2008). Invisible wounds of war: Psychological and cognitive injuries their consequences, and services to assist recovery. Santa Monica, CA: The RAND Corporation.

Viswanathan, M., Ammerman, A., Eng, E., Gartlehner, G., Lohr, K. N., Griffith, D., . . .Whitener, L. (2004). Community-Based Participatory Research: Assessing the evidence. Evidence Report/Technology Assessment No. 99 (Prepared by RTI- 
University of North Carolina Evidence-based Practice Center under Contract No. 290-02-0016). AHRQ Publication 04-E022-2. Rockville, MD: Agency for Healthcare Research and Quality.

Weiner, E., \& Wiener, J. (1997). University students with psychiatric illness: Factors involved in the decision to withdraw from their studies. Psychiatric Rehabilitation Journal, 20, 88-91.

\section{Author's note:}

Address correspondence to: Dr. Alexa M. Smith-Osborne, School of Social Work, University of Texas at Arlington, 211 S. Cooper Street, Box 19129, Arlington, Texas, 76019-0129. E-mail: alexaso@uta.edu. 